\title{
Sağlıkla ilgili eğitim veren fakültelerdeki öğrencilerin uyku kalitesinin belirlenmesi
}

\author{
Determination of sleep quality of students in faculties providing health education
}

\author{
Ahmet Ergin, Güliz Aydemir Acar, Türker Bekar
}

Gönderilme tarihi: 05.07.2017

Kabul tarihi: 26.03 .2018

\section{Özet}

Amaç: Bu araştırmanın amacı sağlık eğitimi alan üniversite birinci öğrencilerinin uyku kalitesinin belirlenmesi ve bazı sağlıklı yaşam davranışlarıyla ilişkisinin incelenmesidir.

Gereç ve yöntem: Kesitsel tipteki bu araştırma Kasım-Aralık 2016 tarihinde yapılmıştır. Araştırmanın evrenini Pamukkale Üniversitesi sağıı eğitimi veren fakültelerdeki birinci sınıf öğrencileri oluşturmuştur.

Bulgular:Araştırmaya katılan toplam öğrenci sayısı 492'dir. Öğrencilerin \%72.2'si kötü uyku kalitesine sahiptir. Öğrencilerin yaş ortalaması $18.5 \pm 1.5$ olup \%65.2'sini kadın öğrenciler oluşturmuştur. Sağlık bilimleri fakültesi öğrencileri diğer bölümlere göre en iyi uyku kalitesine sahiptir. Ailede uyku bozukluğunun olması, enerji içeceği içme ve apart veya yurtta kalma kötü uyku kalitesi için bağımsız risk faktörleri olarak bulunmuştur.

Sonuç:Sonuç olarak öğrencilerin büyük çoğunluğu kötü uyku kalitesine sahiptir. Kötü uyku kalitesi öğrencinin bölümü, kaldığı yer, ailede uyku bozukluğu öyküsü olması ve enerji içeceği kullanması ile ilişkilidir.

Anahtar sözcükler:Uyku, üniversite, tıp fakültesi, öğrenci, sağlık

Ergin A, Aydemir-Acar G, Bekar T. Sağlıkla ilgili eğitim veren fakültelerdeki öğrencilerin uyku kalitesinin belirlenmesi. Pam Tıp Derg 2018;11(3);347-354.

\begin{abstract}
Purpose: The purpose of this study is to determine the sleep quality of the first year students of health education and to examine the relation with some healthy life behaviors.

Materials and methods: This cross-sectional study was conducted between November-December 2016. The universe of the research is the first year students in the faculties of Pamukkale University health education. It was aimed to involve all individuals in the field of the research. In the question form with 48 questions, socio demographic characteristics, nutrition characteristics, physical activity level, smoking habits, alcohol addiction and screen usage of the students were questioned. The sleep quality of the students was assessed by the Pittsburg Sleep Quality Index (PUKI).

Results: The total number of students participating in the survey is $492.72 .2 \%$ of students in this cross-sectional study had poor sleep quality. The average age of the students was $18.5 \pm 1.5$ and $65.2 \%$ were female students. Health science faculty students have the best sleep quality compared to other departments. The presence of sleep disorders in the family, consuming energy drink, and staying at apart home or dormitory were found to be independent risk factors for poor sleep quality.

Conclusion:As a result, the majority of students have poor sleep quality. The poor sleep quality is related to the student's department, the place he or she stays, the story of sleep disorders in the family, and the use of energy drink.
\end{abstract}

Key words: Sleep, university, schools medical, students, health

Ergin A, Aydemir-Acar G, Bekar T. Determination of sleep quality of students in faculties providing health education. Pam Med J 2018;11(3):347-354

Ahmet Ergin, Prof. Dr., Pamukkale Üniversitesi Tıp Fakültesi, Halk Sağlığı Anabilim Dalı, DENiZLí, e-posta: aergin@pau.edu.tr (orcid.org/00000001-5236-7507)

Güliz Aydemir Acar, Arş. Gör. Dr., Pamukkale Üniversitesi Tıp Fakültesi, Halk Sağlığı Anabilim Dalı, DENiZLí, e-posta: glz.1986@outlook.com (orcid.org/0000-0002-8170-4530) (Sorumlu yazar)

Türker Bekar , Arş. Gör. Dr., Pamukkale Üniversitesi Tıp Fakültesi, Halk Sağlığı Anabilim Dalı, DENiZLí, e-posta: tbekar@pau.edu.tr (orcid. org/0000-0002-8231-0269) 


\section{Giriş}

Yaşamımızın ortalama üçte birini oluşturan uyku kişinin duyusal veya diğer uyarılarla uyanabileceği bilinçsizlik durumudur. Uyku kalitesi ise bireyin uyandıktan sonra kendini zinde, formda ve yeni bir güne hazır hissetmesidir. Uyku kalitesi, uyku süresi, derinliği, uykuyu bölen uyanmaların sayısı gibi nicel durumları içerirken, uyku derinliği ve uyku rahatığı gibi nitel durumları da içermektedir [12].

Uyku, bireyin yaşam kalitesini ve iyilik durumunu etkileyen sağlığın önemli bir değişkenidir [3]. Genetik, beslenme, fizik aktivite, genel sağlık durumu gibi pek çok bireysel faktör ve sosyal çevre uyku kalitesini etkilemektedir. Amerika Hastalık Kontrol ve Korunma Merkezleri (CDC), 18-60 yaşındaki bireylerin optimal iyilik hali için en az yedi saat uyuması gerektiğini belirtmektedir. Buna rağmen CDC' ye göre her üç yetişkinden biri yetersiz uyumaktadır. Her yedi saatten az olan uyku artmış obezite, diyabet, yüksek kan basıncı, kalp hastalığı, inme ve ruhsal hastalıklarla ilişkilidir. Yetersiz uyku, stresin ve sağlıktan ödün vermeyi gerektiren bir yaşam şeklinin de işareti olabilmektedir [4].

Toplumlara ve yaş gruplarına göre değişmekle birlikte, uyku bozukluklarının sıklığı \%5-\%71 arasında değişmektedir. Üniversite öğrencilerinde de uyku sorunlarının sık görüldüğü ve uyku kalitelerinin kötü olduğu bilinmektedir [5].

Sağlık eğitimi veren yüksek okullarda yürütülen eğitim programlarının yoğun ve yorucu olmasına bağlı olarak, öğrencilerin uyku zamanlarından fedakarlık etmeleri olasıdır [6]. Sağlıklı yaşam tarzının parametreleri arasında yer alan yeterli ve kaliteli uykunun sağlanması için mevcut durumun belirlenmesi, ilişkili etmenlerin incelenmesi gerekmektedir.

Bu araştırmanın amacı, sağlık eğitimi veren dört farklı fakültede (Tıp Fakültesi, Diş hekimliği Fakültesi, Sağlık Bilimleri Fakültesi, Fizik tedavi ve Rehabilitasyon Fakültesi) öğrenim görmekte olan birinci sınıf öğrencilerinin uyku kalitesinin belirlenmesi ve bazı sağlıklı yaşam davranışlarıyla ilişkisinin incelenmesidir.

\section{Gereç ve yöntem}

Kesitsel tipteki bu araştırma, Kasım-Aralık 2016 tarihleri arasında gerçekleştirilmiştir. Araştırmanın evrenini, Denizli Pamukkale Üniversitesi Tıp Fakültesi, Diş hekimliği Fakültesi, Fizik Tedavi ve Rehabilitasyon Fakültesi ve Sağlık Bilimleri Fakültesi'nde öğrenim gören birinci sınıf öğrencileri oluşturmuştur. Evrendeki tüm bireylerin araştırmaya katılımı hedeflenmiştir. Gerekli etik kurul izinleri alınarak, 9-16 Aralık 2016 tarihleri arasında araştırmanın verileri toplanmıştır. Öğrencilerin uyku kalitesini ve etkileyen faktörleri sorgulayan, 48 sorudan oluşan anket formu çalışmaya katılmaya gönüllü öğrenciler tarafından doldurulmuştur. Anket formunda katılımcının sosyo demografik özelliklerini, beslenme özelliklerini, fizik aktivite düzeyini, sigara, alkol alışkanlığını ve ekran kullanımını sorgulayan 29 soru bulunmaktadır. Beslenme özellikleri verisi için, tüketilen çay, kahve, meşrubat (kola, gazlı içecek) (gün/ hafta) ve enerji içeceği (gün/son bir ay) sorgulanmıştır. Fizik aktivite düzeyi verisi için, DSÖ'nün yetişkinler için önerdiği minimal fizik aktivite düzeyi (dakika/hafta) kesme noktası 77alınarak, son bir aydaki fiziksel aktivite düzeyi sorgulanmıştır [7]. Orta şiddetli ve şiddetli fizik aktivite tipleri, Uluslararası Fiziksel Aktivite Anketi (IPAQ) ölçeğinden yararlanılarak belirtilmiştir. Alkol tüketimi için son bir ay içindeki haftalık alkol tüketimi sıklığı sorgulanmıştır. Yanıt seçenekleri, hiç, haftalık içmeyen, haftada birkaç gün, haftada üç-altı gün veya haftada her gün içen olarak oluşturulmuştur [8].

Öğrencilerin uyku kalitesi Pittsburgh Uyku Kalitesi İndeksi (PUKI) ile değerlendirilmiştir. PUKI son bir ay içerisindeki uyku kalitesi ve uyku bozukluğunun tipi ve şiddeti konusunda bilgi sağlayan bir ölçektir. Toplam 24 soru içeren PUKI ölçeğinde yer alan 19 soru bireyin kendisi tarafından cevaplanmaktadır. Kişi tarafından cevaplanan 19 soru ile öznel uyku kalitesi, uyku kalitesi, uyku süresi, alışımış uyku etkinliği, uyku bozukluğu, uyku ilacı kullanımı, gündüz işlev bozukluğu olarak yedi alt boyut değerlendirilir [9]. Ölçekteki her bir madde sıfır (hiç sıkıntı olmaması)-üç (ciddi sıkıntı) puan arasında değer almaktadır. Yedi alt boyuta ilişkin puanların toplamı ise toplam PUKI puanını vermektedir. Her bir alt boyutun puanı sıfır ile üç puan arasında değişmekte olup, toplam PUKI ise 0-21 arasında puan almaktadır. Toplam 
puanı beş ve altında olanların uyku kalitesi "iyi" olarak değerlendirilmektedir. Ölçeğin Türkçe geçerlilik ve güvenilirlik çalışması Ağargün tarafından yapılmış olup iç tutarlılık katsayısı 0,80 olarak bulunmuştur [3].

Araştırmanın bağımlı değişkenini öğrencilerin uyku kalitesi, araştırmanın bağımsız değişkenlerini ise öğrencinin yaşı, cinsiyeti, yaşadığı yer, anne ve baba eğitim durumu, öğrenim gördüğü fakülte, gelir getirici işte çalışması, beslenme özellikleri, fiziksel aktivite düzeyi, ekran kullanımı, sağıı durumu, beden kitle indeksi (BKi), sigara ve alkol alışkanlığı oluşturmuştur.

İstatiksel analizler için SPSS programı kullanıımıştır. İsim verileri için frekans ve yüzde, sayısal veriler için ortalama ve standart sapma hesaplanarak tanımlayıcı istatistikler verilmiştir. Uyku kalitesi ile ilişkili faktörler ki kare analiziyle değerlendirilmiştir. Çok değişkenli regresyon modeli kullanılarak farklı etkenlerin uyku kalitesi üzerindeki bağımsız etkileri incelenmiş; $p$ değeri $<0,05$ anlamlı kabul edilmiştir.

\section{Bulgular}

Araştırmaya katılan öğrenci sayısı 492'dir (\%75.9). Araştırmaya Tıp Fakültesi öğrencilerinin \% 69.4’ü, Diş Hekimliği Fakültesi öğrencilerinin \%69.5'i, Fizik Tedavi ve Rehabilitasyon Fakültesi öğrencilerinin \%69.2'si, Sağlık Bilimleri Fakültesi öğrencilerinin \%93.6'sı katılmıştır. Öğrencilerin yaş ortalaması 18.5 \pm 1.5 olup \%65.2'sini kadın öğrenciler oluşturmuştur. Araştırmaya katılanların \% 70.1'i apart oda veya yurtta, \%29.3'ü evde arkadaşları veya ailesiyle yaşamaktadır. Öğrencilerin \%14.3'ü halen sigara içmekteydi. Öğrencilerin \%75.2'si hiç alkol kullanmamakta, \%16.3'ü arada sırada, $\% 8.3$ 'ü haftada birkaç kere ve üzerinde alkol kullanmaktadır.

Öğrencilerin \%19.1'i haftada 150 dakika ve üstünde orta şiddetli fiziksel aktivite, \%11.8'i de haftada 75 dakika ve üzerinde şiddetli fiziksel aktivite yapmaktadır. Öğrencilerin \%64.2'si uyumadan önce son bir saatte, $\% 74.0$ 'ü uyumadan önce yatak içinde, cep telefonu veya tablet kullanmaktadır.

Araştırmada öğrencilerin PUKI puan ortalaması: $7.9 \pm 3.4$ olup; $\% 72.2$ 'si kötü uyku kalitesine sahiptir. En iyi uyku kalitesi Sağlık Bilimleri Fakültesi öğrencilerinde en kötü uyku kalitesi Diş Hekimliği Fakültesi öğrencilerinde bulunmuştur $(p=0.001)$. Cinsiyet ile uyku kalitesi arasında fark yoktur $(p=0.710)$. Apart oda veya yurtta yaşayanlar evde yaşayanlara göre daha kötü uyku kalitesine sahip olarak bulunmuştur $(p<0.001)$. Araştırmamızda çay tüketimi (gün/ hafta) ile uyku kalitesi ilişkili bulunmazken, kahve tüketimi ve kafeinli meşrubat tüketimi arttıkça kötü uyku kalitesi sıklığı artmıştır $(p<0.05)$. Günün her saati kafeinli içecek tüketenler yalnız gündüz ve akşam saatlerinde kahve tüketenlere göre daha kötü uyku kalitesine sahiptir $(p=0.027)$. Enerji içeceği (gün/ay) kullananlar kullanmayanlara göre daha kötü uyku kalitesine sahiptir $(p=0.022)$. Fiziksel aktiviteyle uyku kalitesi arasında anlamlı fark bulunmamıştır. Sigara içenler daha kötü uyku kalitesine sahip olarak bulunmuştur ( $p=0.036)$.

Uyumadan önce yatak içinde ekran kullanımı uyku kalitesiyle ilişkili bulunmuştur. Uyumadan önce yatak içi cep telefonu/tablet veya bilgisayar kullananlarda kötü uyku kalitesi daha sıktır $(p=0.028)$. Öğrencilerin beden kitle indeksi, hastalık durumu ve ilaç kullanımı ile uyku kalitesi arasında ilişki yoktur. Ailesinde uyku bozukluğu öyküsü olanlar daha kötü uyku kalitesine sahiptir $(p<0.003)$. Tablo 1 ve Tablo 2 'de iyi ve kötü uyku kalitesiyle ilişkili etmenler görülmektedir.

Çoklu analizde sağlık bilimleri referans alındığında diş hekimliği fakültesinde okuyanlarda 3.51 kat (\%95 Cl:1.36-9.05), tıp fakültesinde okuyanlarda 2,42 kat (\%95 Cl:1.41-4.16), fizik tedavi ve rehabilitasyon fakültesinde okuyanlarda ise 1.62 kat (\%95 Cl:0.87-3.03) daha fazla kötü uyku kalitesi olduğu görülmektedir $(p=0.003)$.

Apart oda ve yurtta kalanlar evde ailesiyle yaşayanlara göre 2.58 kat (\%95 Cl:0.93-7.13), evde arkadaşlarıyla kalanlarsa 2.68 kat (\%95 Cl:1.61-4.47) daha kötü uyku kalitesine sahiptir $(p<0.001)$.

Ailede uyku bozukluğu öyküsü olanlar, olmayanlara göre 2.91 kat (\%95 Cl:1.37-6.19) daha fazla kötü uyku kalitesine sahip olarak bulunmuştur $(p<0.009)$.

Enerji içeceği içenler, içmeyenlere göre 2.63 kat (\%95 Cl:1.05-6.55) daha fazla kötü uyku kalitesine sahiptir $(p=0.039)$ (Tablo 3 ). 
Tablo 1. İyi ve kötü uyku kalitesinin sosyo demografik etmenlerle ilişkisi

\begin{tabular}{|c|c|c|c|}
\hline & $\begin{array}{c}\text { İyi uyku kalitesi } \\
\text { n (\%) } \\
\end{array}$ & $\begin{array}{c}\text { Kötü uyku kalitesi } \\
\text { n (\%) }\end{array}$ & $p$ \\
\hline TOPLAM & $119(24.2)$ & $355(72.2)$ & \\
\hline \multicolumn{4}{|l|}{ Bölüm } \\
\hline Tıp Fak. & $35(20.2)$ & $138(79.8)$ & 0.001 \\
\hline Diş Hekimliği Fak. & $7(12.7)$ & $48(87.3)$ & \\
\hline Fizik Tedavi ve Rhb. Fak. & $22(22.9)$ & $74(77.1)$ & \\
\hline Sağlık Bilimleri Fak. & $55(36,7)$ & $95(63.3)$ & \\
\hline \multicolumn{4}{|l|}{ Cinsiyet } \\
\hline Erkek & $40(24.1)$ & $126(75.9)$ & 0.710 \\
\hline Kadın & $79(25.6)$ & $229(74.4)$ & \\
\hline \multicolumn{4}{|l|}{ Yaş } \\
\hline 18 ve altı & $65(28.8)$ & $161(71.2)$ & 0.065 \\
\hline 19 ve üzeri & $51(21.3)$ & $188(78.7)$ & \\
\hline \multicolumn{4}{|l|}{ Yaşadığı yer } \\
\hline Apart oda /Yurt & $67(20.2)$ & $264(79.8)$ & 0.001 \\
\hline Evde arkadaşlarla & $7(24.1)$ & $22(75.9)$ & \\
\hline Evde aileyle & $44(39.6)$ & $67(60.4)$ & \\
\hline \multicolumn{4}{|l|}{ İşte Çalışma } \\
\hline Çalışan & $2(13.3)$ & $13(86.7)$ & 0.291 \\
\hline Çalışmayan & $116(25.3)$ & $342(74.7)$ & \\
\hline \multicolumn{4}{|l|}{ Anne Eğitimi } \\
\hline Lise ve altı & $96(25.7)$ & $278(74.3)$ & 0.512 \\
\hline Üniversite ve üzeri & $116(22.4)$ & $76(77.6)$ & \\
\hline \multicolumn{4}{|l|}{ Baba Eğitimi } \\
\hline Lise ve altı & $82(27.2)$ & $220(72.8)$ & 0.184 \\
\hline Üniversite ve üzeri & $37(21.6)$ & $134(78.4)$ & \\
\hline
\end{tabular}

Fak.: Fakültesi, Rhb: Rehabilitasyon

Tablo 2. İyi ve kötü uyku kalitesinin beslenme, fizik aktivite ve ekran kullanım özellikleriyle ilişkisi

\begin{tabular}{|c|c|c|c|}
\hline & $\begin{array}{c}\text { İyi uyku kalitesi } \\
\mathrm{n}(\%)\end{array}$ & $\begin{array}{c}\text { Kötü uyku kalitesi } \\
\text { n (\%) }\end{array}$ & $p$ \\
\hline \multicolumn{4}{|l|}{ Çay Tüketimi (gün/hf) } \\
\hline Hiç & $9(21.5)$ & $35(79.5)$ & 0.398 \\
\hline 1-4 gün & $32(29.6)$ & $76(70.4)$ & \\
\hline 4 günden fazla & $76(24.1)$ & $239(75.9)$ & \\
\hline \multicolumn{4}{|l|}{ Kahve Tüketimi (gün/hf) } \\
\hline Hiç & $21(30.9)$ & $47(69.1)$ & 0.038 \\
\hline 1-4 gün & $57(28.2)$ & $145(71.8)$ & \\
\hline 4 günden fazla & $36(18.7)$ & $157(81.3)$ & \\
\hline \multicolumn{4}{|l|}{ Kafeinli Meşrubat Tüketimi (gün/hf) } \\
\hline Hiç & $45(30.6)$ & $102(69.4)$ & 0.012 \\
\hline 1-4 gün & $59(24.0)$ & $187(76.0)$ & \\
\hline 4 günden fazla & $7(11.3)$ & $55(88.7)$ & \\
\hline
\end{tabular}




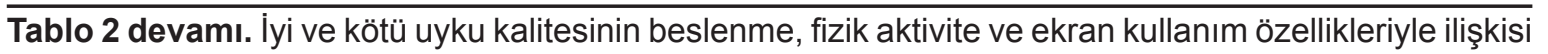

Kafeinli İçecek Tüketim Zamanı

\begin{tabular}{|c|c|c|c|}
\hline Gündüz & $32(25.6)$ & $93(74.4)$ & 0.027 \\
\hline Akşam & $50(31.3)$ & $110(68.8)$ & \\
\hline Her zaman & $33(18.6)$ & $144(81.4)$ & \\
\hline \multicolumn{4}{|l|}{ Enerji İçeceği (gün/ay) } \\
\hline İçmeyen & $113(26.8)$ & $308(73.2)$ & 0.022 \\
\hline İçen & $6(12.0)$ & $44(88.0)$ & \\
\hline \multicolumn{4}{|l|}{ Orta Şiddetli Fizik Aktivite } \\
\hline > $150 \mathrm{Dk}$ & $21(23.1)$ & $70(76.9)$ & 0,057 \\
\hline$<150 \mathrm{Dk}$ & $93(26.0)$ & $265(74,0)$ & \\
\hline \multicolumn{4}{|l|}{ Şiddetli Fizik Aktivite } \\
\hline$>75 \mathrm{Dk}$ & $16(29.1)$ & $39(70.9)$ & 0.494 \\
\hline$<75 \mathrm{Dk}$ & $97(24.8)$ & $294(75.2)$ & \\
\hline \multicolumn{4}{|l|}{ Sigara İçme Durumu } \\
\hline İçiyor & $10(14.9)$ & $57(85.1)$ & 0.036 \\
\hline İçmiyor & $108(26.9)$ & $293(73.1)$ & \\
\hline \multicolumn{4}{|l|}{ Alkol Tüketimi* } \\
\hline Hiç içmeyen & $98(27.5)$ & $258(72.5)$ & 0.074 \\
\hline Sosyal içici & $19(17.4)$ & $90(82.6)$ & \\
\hline Düzenli içici & $1(12.5)$ & $7(87.5)$ & \\
\hline \multicolumn{4}{|l|}{ Uyunan Odada TV } \\
\hline Var & $17(27,4)$ & $45(72.6)$ & 0,699 \\
\hline Yok & $102(25.1)$ & $304(74.9)$ & \\
\hline \multicolumn{4}{|l|}{ Uyumadan Önce Son 1 Saat Ekran Kullanımı } \\
\hline TV & $15(38.5)$ & $24(61.5)$ & 0.167 \\
\hline Bilgisayar & $12(22.2)$ & $42(78.8)$ & \\
\hline Cep tel./Tablet & $70(23.0)$ & $235(77.0)$ & \\
\hline Hiçbiri & $20(28.2)$ & $51(718)$ & \\
\hline \multicolumn{4}{|l|}{ Uyumadan Önce Yatak İçi Ekran Kullanımı } \\
\hline TV & $8(57.1)$ & $6(42,9)$ & 0.028 \\
\hline Bilgisayar & $6(24.0)$ & $19(76.0)$ & \\
\hline Cep tel./Tablet & $82(23.2)$ & $271(76.8)$ & \\
\hline Hiçbiri & $22(29.2)$ & $52(70.3)$ & \\
\hline \multicolumn{4}{|l|}{ BKi } \\
\hline Zayıf & $13(27.7)$ & $34(72.3)$ & 0.970 \\
\hline Normal & $83(24.5)$ & $256(75.5)$ & \\
\hline Fazla kilolu & $16(25.8)$ & $46(74.2)$ & \\
\hline Obez & $3(25.0)$ & $9(75.0)$ & \\
\hline \multicolumn{4}{|l|}{ Hastalık } \\
\hline Var & $10(16.9)$ & $49(83.1)$ & 0.118 \\
\hline Yok & $109(26.4)$ & $304(73.6)$ & \\
\hline \multicolumn{4}{|l|}{ İlaç Kullanımı } \\
\hline Var & $8(14.8)$ & $46(85.2)$ & 0.064 \\
\hline Yok & $111(26.4)$ & $309(73.6)$ & \\
\hline \multicolumn{4}{|l|}{ Ailesel Uyku Bozukluğu Öyküsü } \\
\hline Var & $10(12.2)$ & $72(87.8)$ & 0.003 \\
\hline Yok & $109(27.9)$ & $281(72.1)$ & \\
\hline
\end{tabular}

*Hiç alkol kullanmayanlar "hiç içmeyen", haftalık tüketmeyenler "sosyal içici", haftada 1-2 gün, haftada 3-4 gün ve haftalık her gün alkol tüketenler "düzenli içici" olarak kategorize edilmiştir. 
Tablo 3. Kötü uyku kalitesiyle ilişkili faktörlerin çok değişkenli analizi

\begin{tabular}{|c|c|c|c|}
\hline & Tahmini rölatif risk & $\% 95 \mathrm{Cl}$ & $p$ \\
\hline \multicolumn{4}{|l|}{ Bölüm } \\
\hline Sağlık Bilimleri Fak. & ref. & & \multirow{4}{*}{0.003} \\
\hline Fizik Tedavi ve Rhb. Fak. & 1.62 & $0.87-3.03$ & \\
\hline Diş Hekimliği Fak. & 3.51 & $1.36-9.05$ & \\
\hline Tıp Fakültesi & 2.42 & $1.41-4.16$ & \\
\hline \multicolumn{4}{|l|}{ Yaşadığı Yer } \\
\hline Ev-aile & ref. & & \multirow{3}{*}{$<0.001$} \\
\hline Apart oda-yurt & 2.58 & $0.93-7.13$ & \\
\hline Ev-arkadaşlar & 2.68 & $1.61-4.47$ & \\
\hline \multicolumn{4}{|l|}{ Ailesel Uyku Bozukluğu } \\
\hline Yok & ref. & & \multirow{2}{*}{0.005} \\
\hline Var & 2.91 & $1.37-6.19$ & \\
\hline \multicolumn{4}{|l|}{ Enerji İçeceği } \\
\hline İçmeyen & ref. & & \multirow{2}{*}{0.039} \\
\hline İçen & 2.63 & $1.05-6.55$ & \\
\hline
\end{tabular}

Modele yaş, cinsiyet, kendine ait odası olması, kafeinli içecek tüketim saati, yatmadan önce son 1 saat içinde ekran kullanımı, yatmadan önce ekran kullanımı, ailede uyku bozukluğu varlığı, çay-kahve-meşrubat-alkol-enerji içeceği tüketim sıklıkları, okulda 5 saat ve üzeri kalma, DSÖ önerdiği miktarda fiziksel aktivite yapma durumu dahil edilmiş, geriye doğru regresyon modeli ile anlamlı olmayanlar modelden çıkarılmıştır.

Fak.: Fakültesi, Rhb: Rehabilitasyon, ref.: referans

\section{Tartışma}

Sağlık eğitimi alan birinci sınıf üniversite öğrencilerinin uyku kalitesini ve etkileyen faktörleri belirlemek amacıyla yaptığımız araştırmada öğrencilerin büyük çoğunluğunun kötü uyku kalitesine sahip olduğu bulunmuştur. Öğrencinin bölümü, yaşanılan yer, ailede uyku bozukluğu öyküsü ve enerji içeceği içme; kötü uyku kalitesi için bağımsız risk faktörleri olarak belirlenmiştir.

Üniversite hayatı sosyal etkinliklerin, arkadaş gruplarıyla faaliyetlerin yoğun olduğu, aynı zamanda gençlerin tam veya yarı zamanlı olarak çalışma hayatına atılabildiği bir dönemdir. Orzech'e [10] göre, uyku ile ilgili problemler özellikle üniversitesinin ilk yılında stres yönetimi eksikliği, aileden uzaklaşma, sosyal çevreye uyum nedeniyle görülebilir. Sağlık eğitimi veren fakültelerde öğrenim gören öğrencilerin yoğun ders müfredatı nedeniyle uykularından ödün vermeleri de olasıdır.

Araştırmamızda kötü uyku kalitesine sahip olma sıklığı \%72.2 bulunurken, en iyiuyku kalitesi Sağlık Bilimleri öğrencilerinde görülmüştür. Aysan'ın [5] sağlık bilimlerinde (hemşirelik/tıp/ eczacılık) 300 öğrenciyle yaptığı çalışmada kötü uyku kalitesi sıklığı \%59 PUKI puanı ortalaması $6.15 \pm 1.90$ bulunmuştur. Hemşirelik öğrencileri en iyi uyku kalitesine sahip olmakla birlikte bölümler arasında anlamlı fark yoktur. Aysan'ın [5] çalışmasında hem analizlerin PUKI puan ortalaması üzerinden yapılması hem de farklı bölümlerdeki öğrencilerin çalışmaya dahil edilmesi bizim sonuçlarımızla farklılığın nedeni olabilir.

Saygılı ve arkadaşları [11] tarafından Sağlık Yüksekokulu, Teknik Bilimler Meslek Yüksekokulu, Sosyal Bilimler Meslek Yüksekokulu, Fen Edebiyat Fakültesi, Sağlık Hizmetleri Meslek Yüksekokulu, İktisadi İdari Bilimler Fakültesi öğrencilerinde 550 kişiyle yapılan çalışmada kötü uyku kalitesi sıklığı \%30.5, PUKİ puan ortalaması: 6.9+2,4 bulunmuştur. Sağlık Yüksekokulu 6.5+2.4 PUKI puan ortalaması ile bizim araştırmamıza benzer şekilde diğer fakültelerden daha iyi uyku kalitesine sahip olarak bulunmuştur.

Dördüncü, beşinci ve altıncı sınıfta öğrenim gören 84 tıp fakültesi öğrencisinde yapılan bir çalışmada Mayda ve ark. [6] kötü uyku

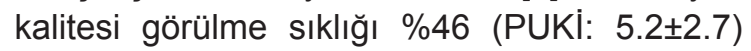
bulunmuştur. Araştırmamızda ise tıp fakültesi öğrencilerinin \%80'nine yakını kötü uyku

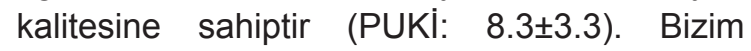
araştırmamızda kötü uyku kalitesi sıklığının daha fazla olması birinci sınıf öğrencilerinin çalışmaya 
dahil edilmesi dolayısıyla üniversitenin ilk yılında uyku problemlerinin daha sık görülmesiyle ilişkili olabilir.

Araştırmamızda apart oda/yurtta kalanlarda kötü uyku kalitesi daha sıktır. Ev ortamına göre öğrenci yurtlarının daha kalabalık; aydınlatma, gürültü gibi fiziksel şartlar yönünden daha uygunsuz olması uyku kalitesini etkiliyor olabilir. Ev ortamının fiziksel şartlarının uygun olması, aileden alınan sosyal desteğin stresi azaltması, ebeveynleriyle yaşayan öğrencilerin daha düzenli bir hayat tarzını benimsemesi bu bulguda etkili olmuş olabilir. Aysan ve arkadaşları [5] tarafından yapılan çalışmada evde ailesiyle kalanlar, evde arkadaşlarıyla ve yurtta kalanlara göre daha iyi uyku kalitesine sahip olmasına rağmen, yaşanılan yer ile uyku kalitesi arasında anlamlı fark bulunmamıştır.

Çalışmamızda ailesel uyku bozukluğu öyküsü olanlar; kötü uyku kalitesi açısından daha riskli bulunmuştur. Uyku kalitesiyle ilgili genetik temeller olabileceği gibi, aileden öğrenilmiş davranış kalıpları da uyku kalitesi üzerinde etkili olabilir. Şenol ve ark. [2] tarafından 300 adolesan ile yapılan bir çalışmada ailevi uyku bozukluğu öyküsü olan, daha önce uyku bozukluğu sorunu yaşayan, geçmiş bedensel ve ruhsal rahatsızlık öyküsü tanımlayan katııımcıların uyku kalitesi anlamlı düzeyde daha düşük saptanmıştır.

Araştırmamızda üniversite öğrencilerinde enerji içeceği kullanma sıklığı \%10.4 olup, Türkiye'de üniversite öğrencilerinde yapılan çalışmalarda bulunan sıklıkların altındadır [1213]. Enerji içeceği kullananlarda kötü uyku kalitesi daha sıktır. Enerji içeceği üniversite öğrencilerinde daha çok fiziksel ve mental performansı artırmak için kullanılmaktadır. Çoğu enerji içeceği sekiz fincan kahveye denk olan $80 \mathrm{mg}$ kafein içerir. Günlük 400 mg'dan fazla kafein tüketimi uykusuzluğu da içine alan çeşitli sağlık yan etkileriyle ilişkilendirilmektedir [14].

Geçerlik ve güvenilirliği gösterilmiş bir ölçek ile uyku kalitesini ölçmemiz ve araştırmamıza katıımın yüksek olması araştırmamızın güçlü yönüdür. Verilerin beyana dayalı olması araştırmanın sınırlıığıdır.

Sonuç olarak sağlık eğitimi veren fakültelerde eğitim gören birinci sınıf öğrencilerinin büyük çoğunluğu kötü uyku kalitesine sahiptir. Öğrencinin bölümü, kaldığı yer, ailesinde uyku bozukluğu olması ve enerji içeceği kullanması uyku kalitesini etkilemektedir. Bu sonuçlara göre; üniversite öğrencilerinin uyku kalitesi konusunda bilgisinin ve farkındalığının arttırılması, yurt ve apartlarda öğrencilerin uyku kalitesini dikkate alan idari düzenlemeler yapılması önerilebilir.

Çıkar İlişkisi: Yazarlar çıkar ilişkisi olmadığını beyan eder.

\section{Kaynaklar}

1. Ünal İ. 40-65 yaş arasındaki bireylerin fiziksel aktivite ile uyku kalitesi arasındaki ilişkinin incelenmesi. Yayınlanmamış Yüksek Lisans Tezi. Gedik Üniversitesi Sağlık Bilimleri Enstitüsü, Hareket ve Antrenman Bilimleri Anabilim Dalı, İstanbul, 2016.

2. Şenol V, Soyuer $F$, Pekşen Akça $R$, Argün $M$. Adolesanlarda uyku kalitesi ve etkileyen faktörler. Kocatepe Tıp Derg 2012;14:93-102.

3. Üstün $Y$, Çınar Yücel Ş. Hemşirelerin uyku kalitesinin incelenmesi. Maltepe Üniversitesi Hemşirelik Bilim ve Sanatı Dergisi 2011;4:29-38.

4. CDC Features. Insufficient Sleep is a Public Health Problem. https://www.cdc.gov/features/dssleep/index. html Erişim tarihi 20 Nisan 2017.

5. Aysan E, Karaköse S, Zaybak A, Günay İsmailoğlu E. Üniversite öğrencilerinde uyku kalitesi ve etkileyen faktörler. DEUHFED 2014;7:193-198.

6. Mayda AS, Kasap H, Yıldırım C ve ark. 4-5-6. sınıf tıp fakültesi öğrencilerinde uyku bozukluğu sıklığı. Düzce Üniversitesi Sağlık Bilimleri Enstitüsü Dergisi 2012;2:811.

7. Global Strategy on Diet, Physical Activity and Health. http://www.who.int/dietphysicalactivity/factsheet_ adults/en/ Erişim tarihi 10 Kasım 2017.

8. Huang R, Ho SY, Lo WS, Lai HK, Lam TH. Alcohol consumption and sleep problems in Hong Kong adolescents. Sleep Med 2013;14:877-882.

9. Yüksel C. Hemşirelerde uyku kalitesi uyku kalitesi iş doyumu ve tükenmişlik arasındaki ilişkinin incelenmesi. Yayınlanmamış Yüksek Lisans Tezi. Eskişehir Osmangazi Üniversitesi Sağlık Bilimleri Enstitüsü, Cerrahi Hastalıkları Hemşirelik Anabilim Dalı Cerrahi Hastalıkları Hemşireliği, 2013.

10. Orzech KM, Salafsky DB, Hamilton LA. The state of sleep among college students at a large public university. J Am Coll Health 2011;59:612-619.

11. Saygılı S, Akıncı Çil A, Arıkan H, Dereli E. Üniversite öğrencilerinde uyku kalitesi ve yorgunluk. Ejovoc 2011;1:88-94. 
12. İsçioğlu $F$, Ova $G$, Duyar $Y$, Köksal M. Üniversite öğrencileri arasındaki enerji içeceği tüketimi ve bilinci araştırmasi. Acad Food J 2010;8:6-11.

13. Bulut B, Beyhun N, Topbaş M, Çan G. Energy Drink Use in University Students and Associated Factors. J Community Health 2014;39:1004-1011.

14. Reid DS, Ramsarran J, Brathwaite R et al. Energy drink usage among university students in a Caribbean country: patterns of use and adverse effects. J Epidemiol Glob Health 2015;5:103-116.

Teşekkür: Katkılarından dolayı Emin Uçar, Nuh Mehmet İnce, Esra Arıcan, Ahmet Cihat Eroğlu, Mahsum Kaya, Seda Ceyhan, M. Oğuz Türkmen, Furkan Gürçay, Kemal Uylaş, Seçil Altınok ve Bedia Karnak’a teşekkür ederiz. 